\title{
IMPROVEMENT OF TILE DRAINAGE SYSTEMS USING MOLE DRAINS
}

\author{
Mohamed .M. Sobeih ${ }^{1}$, Ibrahim M. Rashwan ${ }^{2}$, Moustafa .A. El-Enany ${ }^{1}$, \\ Eman .M. Foda ${ }^{1}$ \\ 1- Civil Engineering Department, Faculty of Engineering, Minoufiya University, \\ Shebin El-Kom, Egypt \\ 2- Civil Engineering Department, Faculty of Engineering, Tanta University, \\ Tanta, Egypt
}

\begin{abstract}
In this paper the problem of draining a heavy clay layer of low hydraulic conductivity over-lying an impermeable layer is treated mathematically by means of a combined system of pipe and mole drains. The complex potential, the stream functions, and the velocity potential are provided. New discharge formulas for both tile and mole drains are established. Formulas for calculating the velocity components at any point are provided. Effects of the different variables, the top clay cap thickness below drain center ,D, mole drain diameter, $\mathrm{d} 2$, height of water above tile drain center midway between two successive tile drains, $\mathrm{H}$, mole spacing , a, and the vertical distance between tile drains and mole drains ,b, are studied.

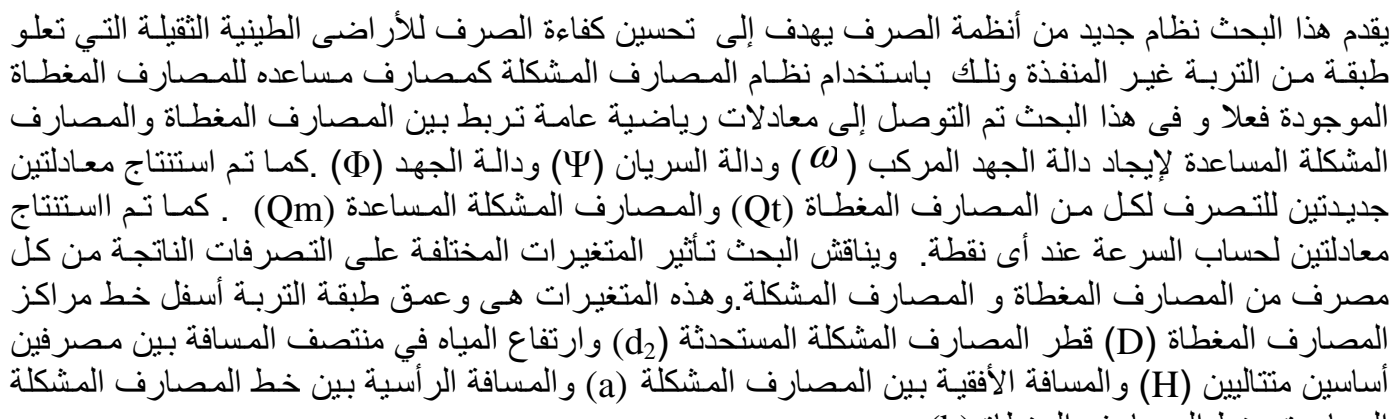

Keywords: Tile drainage, Mole drainage, subsurface drainage

\section{INTRODUCTION}

The direct aim of drainage systems in humid regions is to lower the moisture content of the upper soil layers so air can penetrate more easily to the roots. This also facilitates the transport of carbon dioxide $\left(\mathrm{Co}_{2}\right)$ produced by roots, microorganisms and chemical reactions is facilitated.

The need to keep productivity of agricultural soil led over a century ago to the use of subsurface drains properly spaced and dimensioned to give perfect control of the subsoil water level. Generally, subsurface drainage system is extensively used for draining agricultural land to increase land productivity and to save existing cultivated areas. The covered drainage system is regarded as the ideal system for drainage. It secures the maximum benefit with the minimum overall cost. The most important systems of covered drains are tile, plastic and mole drainage systems. Mole drains system is the cheapest and the simplest mean for draining agricultural lands (1, 2 \& 3).
In the present paper, the problem of draining a heavy clay layer of low hydraulic conductivity over-lying an impermeable layer is treated mathematically by means of a combined system of pipe and mole drains. Figure 1 represents the geometry of the problem.

\section{BASIC ASSUMPTIONS AND BOUNDARY CONDTIONS}

The basic assumptions that were put forward were as follow:

1- Tile drains are running full but mole drains are running nearly empty.

2- Tile drains are equal in strength $(\mathrm{M})$ and also, mole drains are equal in strength $(\mathrm{m})$.

3- The soil is regarded as homogeneous and isotropic.

4- On the free water surface, the pressure is atmospheric.

5- The normal gradient of $\theta$ disappears along the vertical lines of symmetry, Fig. (1).

6- The dotted vertical lines of Fig. (1) are lines of symmetry and therefore, no flow occurs across them. 


\section{HYDRODYNAMICAL ANALYSIS}

The flow pattern may be simulated by assuming two rows of drains. The first raw consists of an infinite number of equal distant mole drains represented by equidistant sinks the strength of each $=\mathrm{m}$. The second raw consists of an infinite number of equally spaced tile (pipe) drains represented by equally spaced sinks the strength of each $=\mathrm{M}$.

The complex potential of equally spaced sinks that represent pipe drains, Fig. 2, is given by:

$$
\omega 1=M \ln \sin \frac{\pi z}{L}+\mathrm{c} 1
$$

Where:

$\mathrm{M}=$ point sink strength,

$\mathrm{Z}=\mathrm{x}+\mathrm{i} \mathrm{y}=$ complex coordinate,

$\mathrm{L}=$ spacing between tile drains,

$i=\sqrt{-1}$ and $\mathrm{c} 1=$ a real constant.

For simplicity let us start with considering three additional tile drains installed within the spacing L, The complex potential of them may be written as.

$$
\begin{aligned}
\omega 2= & m \cdot \operatorname{In} \sin \frac{\pi}{L}(z-i b)+m \cdot \operatorname{In} \sin \frac{\pi}{L}(z-a-i b) \\
& +m \cdot \operatorname{In} \sin \frac{\pi}{L}(z+a-i b)+c 2
\end{aligned}
$$

Where:

$\mathrm{m}=$ point sink strength,

$\mathrm{b}=$ vertical spacing between lines of tile drains and additional mole drains,

$\mathrm{a}=$ spacing between sinks and

$\mathrm{c} 2=\mathrm{a}$ real constant.

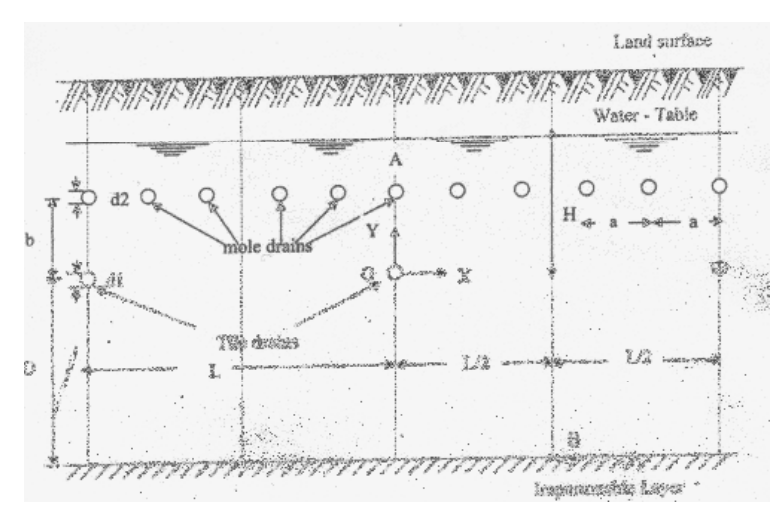

Fig. 1 Geometry of problem

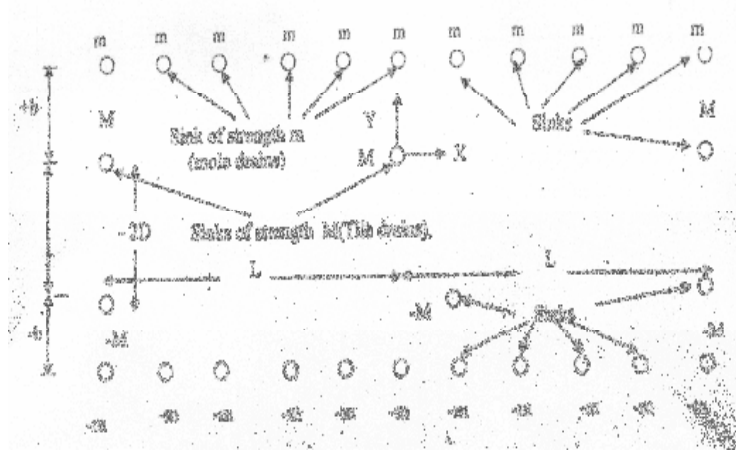

Fig. 2 Mathematical model

To represent the lower impervious layer it might be considered as a mirror and hence it might be replaced by the images of imaginary sinks shown in Fig. 2 . The complex potential of fictitious sinks of strength $\mathrm{M}$ is represented as follows:

$$
\omega 3=M \cdot \operatorname{In} \sin \frac{\pi}{L}(z+2 i D)+c 3
$$

Where $\mathrm{c} 3=$ a real constant.

The complex potential of fictitious sinks of strength $\mathrm{m}$ is given by:

$$
\begin{aligned}
\omega 4= & M \cdot \operatorname{In} \sin \frac{\pi}{L}(z+2 i D+i b) \\
& +m \cdot \operatorname{In} \sin \frac{\pi}{L}(z+2 i D-a-i b) \\
& +m \cdot \operatorname{In} \sin \frac{\pi}{L}(z+2 i D+a+i b)+c 4
\end{aligned}
$$

Where $\mathrm{C} 4=$ real constant

Therefore, the complex potential of the system is obtained simply by adding complex potentials (1) through (4)

$$
\omega 5=\omega 1+\omega 2+\omega 3+\omega 4+\mathrm{C} 5
$$

Where $\mathrm{C} 5=$ real constant

Substituting $\mathrm{z}=\mathrm{x}+\mathrm{iy}$,

In which: $i=\sqrt{-1}$, and simplifying:

$$
\begin{gathered}
\omega=M \cdot \ln \left[\sin \frac{\pi x}{L} \cdot \cosh \frac{\pi y}{L}+i \cos \frac{\pi x}{L} \cdot \sinh \frac{\pi y}{L}\right] \\
+M \cdot \ln \left[\begin{array}{l}
\sin \frac{\pi x}{L} \cdot \cosh \pi \frac{(y+2 D)}{L} \\
+i \cos \frac{\pi x}{L} \cdot \sinh \pi \frac{(y+2 D)}{L}
\end{array}\right] \\
+m \cdot \ln \left[\begin{array}{l}
\sin \frac{\pi x}{L} \cdot \cosh \pi \frac{(y-b)}{L} \\
+i \cos \frac{\pi x}{L} \cdot \sinh \pi \frac{(y-b)}{L}
\end{array}\right]
\end{gathered}
$$


Mohamed.M. Sobeih, Ibrahim M. Rashwan, Moustafa .A. El-Enany, Eman .M. Foda, "Improvement of ..."

$$
\begin{array}{r}
+m \cdot \ln \left[\begin{array}{l}
\sin \pi \frac{(x-a)}{L} \cdot \cosh \pi \frac{(y-b)}{L} \\
+i \cos \pi \frac{(x-a)}{L} \cdot \sinh \pi \frac{(y-b)}{L}
\end{array}\right] \\
+m \cdot \ln \left[\begin{array}{l}
\sin \pi \frac{(x+a)}{L} \cdot \cosh \pi \frac{(y-b)}{L} \\
+i \cos \pi \frac{(x+a)}{L} \cdot \sinh \pi \frac{(y-b)}{L}
\end{array}\right] \\
+m \cdot \ln \left[\begin{array}{l}
\sin \frac{\pi x}{L} \cdot \cosh \pi \frac{(y+b+2 D)}{L} \\
+i \cos \frac{\pi x}{L} \cdot \sinh \pi \frac{(y+b+2 D)}{L}
\end{array}\right] \\
+m \cdot \ln \left[\begin{array}{l}
\sin \pi \frac{(x-a)}{L} \cdot \cosh \pi \frac{(y+b+2 D)}{L} \\
+i \cos \pi \frac{(x-a)}{L} \cdot \sinh \pi \frac{(y+b+2 D)}{L}
\end{array}\right]+\mathrm{c} 5
\end{array}
$$

Substituting $\omega=\Phi+i \Psi$

Where,

$\Phi=$ velocity potential and $\Psi=$ stream function

Equating real to real and imaginary to imaginary on both sides of the above equation and simplifying we get:

$$
\begin{aligned}
& \Phi=M / 2 . \operatorname{In}\left\{\begin{array}{l}
{\left[\sin ^{2} \pi x / L+\sinh ^{2} \pi y / L\right]} \\
*\left[\sin ^{2} \pi x / L+\sinh ^{2} \pi(y+2 D) / L\right]
\end{array}\right\} \\
& +m / 2 \cdot \sum_{0}^{n} \operatorname{In}\left\{\begin{array}{l}
{\left[\begin{array}{l}
\sin ^{2} \pi(x-n a) / L \\
+\sinh ^{2} \pi(y-b) / L
\end{array}\right]} \\
*\left[\begin{array}{l}
\sin ^{2} \pi(x-n a) / L \\
+\sinh ^{2} \pi(y+2 D+b) / L
\end{array}\right]
\end{array}\right\} \\
& +m / 2 \cdot \sum_{1}^{n} \operatorname{In}\left\{\begin{array}{l}
{\left[\begin{array}{l}
\sin ^{2} \pi(x+n a) / L \\
+\sinh ^{2} \pi(y-b) / L
\end{array}\right]} \\
*\left[\begin{array}{l}
\sin ^{2} \pi(x+n a) / L \\
+\sinh ^{2} \pi(y+2 D+b) / L
\end{array}\right]
\end{array}\right\} \\
& \Psi=M \cdot \tan ^{-1}\left[\cot \frac{\pi x}{L} \cdot \tanh \frac{\pi y}{L}\right] \\
& +M \cdot \tan ^{-1}\left[\cot \frac{\pi x}{L} \cdot \tanh \pi \frac{(y+2 D)}{L}\right] \\
& { }^{+} M \cdot \sum_{0}^{n} \tan ^{-1}\left[\cot \frac{\pi(x-n a)}{L} \cdot \tanh \pi \frac{(y-b)}{L}\right] \\
& +M \cdot \sum_{1}^{n} \tan ^{-1}\left[\cot \frac{\pi(x+n a)}{L} \cdot \tanh \pi \frac{(y+2 D+b)}{L}\right]
\end{aligned}
$$

\section{VELOCITY CONSIDERATIONS}

The velocity components at any point in the flow field are given by:

$\mathrm{u}=-\partial \Phi / \partial x$

$\mathrm{v}=-\partial \Phi / \partial y$

In which $\mathrm{u}$ and $\mathrm{v}$ are the velocity components in the $\mathrm{X}$ and $\mathrm{y}$ directions respectively.

Differentiating Eq. (7) partially, with respect to $\mathrm{X}$ and simplifying; the horizontal velocity component $\mathrm{u}$, will lead to:

$$
u=-\frac{M \pi}{2 L} \cdot\left\{\begin{array}{l}
\frac{(\sin 2 \pi x / L)}{\left[\sin ^{2} \frac{\pi x}{L}+\sinh ^{2} \frac{\pi y}{L}\right]} \\
+\frac{(\sin 2 \pi x / L)}{\left[\sin ^{2} \frac{\pi x}{L}+\sinh ^{2} \frac{\pi(y+2 D)}{L}\right]}
\end{array}\right\}
$$$$
-\frac{m \pi}{2 L} \cdot \sum_{0}^{n}\left\{\begin{array}{l}
\frac{[\sin 2 \pi(x-n a) / L]}{\left[\sin ^{2} \frac{\pi(x-n a)}{L}+\sinh ^{2} \frac{\pi(y-b)}{L}\right]} \\
+\frac{[\sin 2 \pi(x-n a) / L]}{\left[\sin ^{2} \frac{\pi(x-n a)}{L}+\sinh ^{2} \frac{\pi(y+b+2 D)}{L}\right]}
\end{array}\right\}
$$

$$
-\frac{m \pi}{2 L} \cdot \sum_{1}^{n}\left\{\begin{array}{l}
\frac{[\sin 2 \pi(x+n a) / L]}{\left[\sin ^{2} \frac{\pi(x+n a)}{L}+\sinh ^{2} \frac{\pi(y-b)}{L}\right]} \\
+\frac{[\sin 2 \pi(x+n a) / L]}{\left[\sin ^{2} \frac{\pi(x+n a)}{L}+\sinh ^{2} \frac{\pi(y+b+2 D)}{L}\right]}
\end{array}\right\}
$$

Similarly, differentiating Eq. (7) partially with respect to $\mathrm{y}$ and simplifying, the vertical velocity component v, will lead to:

$$
v=-\frac{M \pi}{2 L} \cdot\left\{\begin{array}{l}
\frac{(\sinh 2 \pi y / L)}{\left[\sin ^{2} \frac{\pi x}{L}+\sinh ^{2} \frac{\pi y}{L}\right]} \\
+\frac{(\sinh 2 \pi(y+2 D) / L)}{\left[\sin ^{2} \frac{\pi x}{L}+\sinh ^{2} \frac{\pi(y+2 D)}{L}\right]}
\end{array}\right\}
$$

In which: $\mathrm{n}=((\mathrm{L} / \mathrm{a})-1) / 2$ 
Mohamed.M. Sobeih, Ibrahim M. Rashwan, Moustafa .A. El-Enany, Eman .M. Foda, "Improvement of ..."

$$
\begin{gathered}
-\frac{m \pi}{2 L} \cdot \sum_{0}^{n}\left\{\begin{array}{l}
\frac{[\sinh 2 \pi(y-b) / L]}{\left.\sin ^{2} \frac{\pi(x-n a)}{L}+\sinh ^{2} \frac{\pi(y-b)}{L}\right]} \\
\left.+\frac{[\sinh 2 \pi(y+b+2 D) / L]}{\left[\sin ^{2} \frac{\pi(x-n a)}{L}+\sinh ^{2} \frac{\pi(y+b+2 D)}{L}\right.}\right]
\end{array}\right\} \\
-\frac{m \pi}{2 L} \cdot \sum_{1}^{n}\left\{\begin{array}{l}
\frac{[\sinh 2 \pi(y-b) / L]}{\left[\sin ^{2} \frac{\pi(x+n a)}{L}+\sinh ^{2} \frac{\pi(y-b)}{L}\right]} \\
+\frac{[\sinh 2 \pi(y+b+2 D) / L]}{\left[\sin ^{2} \frac{\pi(x+n a)}{L}+\sinh ^{2} \frac{\pi(y+b+2 D)}{L}\right.}
\end{array}\right\}
\end{gathered}
$$

\section{DISCHARGE FORMULAS}

The velocity potential of flow, $\Phi$, might be put in this form:

$\Phi=k[\mathrm{p} /(\rho g+y)]$

Where $\mathrm{K}=$ the hydraulic conductivity of soil, $\mathrm{P}=$ gauge pressure, $\rho=$ density of drained water, $\mathrm{g}=$ acceleration due to gravity and $\mathrm{y}=$ vertical coordinate of a point.

From Eqs . (7) and (13), we get:

$$
\begin{aligned}
& K\left(\frac{P}{P g+y}\right) \\
& =M / 2 \cdot \operatorname{In}\left\{\begin{array}{l}
{\left[\sin ^{2} \pi x / L+\sinh ^{2} \pi y / L\right]} \\
*\left[\begin{array}{l}
\sin ^{2} \pi x / L+\sinh ^{2} \pi(y+2 D) / L
\end{array}\right]
\end{array}\right\} \\
& +m / 2 \cdot \sum_{0}^{n} \operatorname{In}\left\{\begin{array}{l}
{\left[\begin{array}{l}
\sin ^{2} \pi(x-n a) / L \\
+\sinh ^{2} \pi(y-b) / L
\end{array}\right]} \\
*\left[\begin{array}{l}
\sin ^{2} \pi(x-n a) / L \\
+\sinh ^{2} \pi(y+2 D+b) / L
\end{array}\right]
\end{array}\right\} \\
& +m / 2 \cdot \sum_{1}^{n} \operatorname{In}\left\{\begin{array}{l}
{\left[\begin{array}{l}
\sin ^{2} \pi(x+n a) / L \\
+\sinh ^{2} \pi(y-b) / L
\end{array}\right]} \\
\left.* \begin{array}{l}
\sin ^{2} \pi(x+n a) / L \\
+\sinh ^{2} \pi(y+2 D+b) / L
\end{array}\right]
\end{array}\right\}
\end{aligned}
$$

Applying Eq. (14) at point $\mathrm{G}(0, \mathrm{~d} / 2)$,one obtains.

$$
\begin{aligned}
K\left(\frac{d 1}{2}\right) & =M / 2 . I n\left[\begin{array}{l}
\sinh ^{2} \frac{\pi d 1}{2 L} \\
* \sinh ^{2} \pi \frac{(d 1 / 2+2 D)}{L}
\end{array}\right] \\
& +m / 2 . I n\left[\begin{array}{l}
\sinh ^{2} \pi \frac{(d 1 / 2-b)}{L} \\
* \sinh ^{2} \pi \frac{(d 1 / 2+b+2 D)}{L}
\end{array}\right]
\end{aligned}
$$

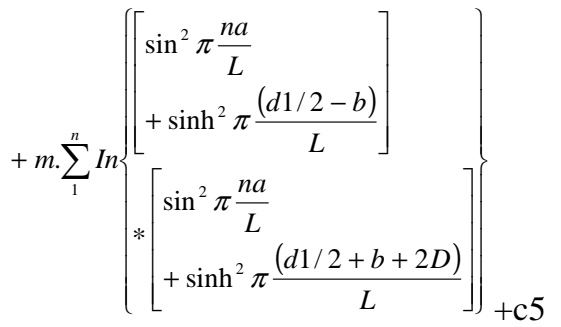

The mole drain is assumed to run nearly empty. Applying Eq.(14) to point A (0, b-d1/2) at the mole drain bottom, the following is obtained:

$$
\begin{array}{r}
K(b-d 2 / 2)=M / 2 . I n\left[\begin{array}{l}
\sinh ^{2} \frac{\pi(b-d 2 / 2)}{L} \\
* \sinh ^{2} \pi \frac{(b+2 D-d 2 / 2)}{L}
\end{array}\right] \\
+m / 2 . I n\left[\begin{array}{l}
\sinh ^{2} \pi \frac{(-d 2 / 2)}{L} \\
* \sinh ^{2} \pi \frac{(2 b+2 D-d 2 / 2)}{L}
\end{array}\right] \\
+m \cdot \sum_{1}^{n} \operatorname{In}\left\{\begin{array}{l}
\sin ^{2} \pi \frac{n a}{L} \\
+\sinh ^{2} \pi \frac{(-d 2 / 2)}{L}
\end{array}\right] \\
\left.\begin{array}{l}
\sin ^{2} \pi \frac{n a}{L} \\
+\sinh ^{2} \pi \frac{(2 b+2 D-d 2 / 2)}{L}
\end{array}\right]+c 5
\end{array}
$$

Applying Eq. (14) to point $\mathrm{F}(\mathrm{L} / 2, \mathrm{H})$ on the free water surface, Fig. 1, it follows.

$$
\left.\begin{array}{c}
K(H)=M / 2 \cdot I n\left[\begin{array}{l}
\cosh ^{2} \frac{\pi H}{L} \\
* \cosh ^{2} \pi \frac{(H+2 D)}{L}
\end{array}\right] \\
+m / 2 \cdot \sum_{0}^{n} I n\left\{\begin{array}{l}
\cos ^{2} \pi \frac{n a}{L} \\
+\sinh ^{2} \pi \frac{(H-b)}{L}
\end{array}\right] \\
*\left[\begin{array}{l}
\cos ^{2} \pi \frac{n a}{L} \\
+\sinh ^{2} \pi \frac{(H+b+2 D)}{L}
\end{array}\right]
\end{array}\right\}
$$

$$
+m / 2 \cdot \sum_{1}^{n} \operatorname{In}\left\{\begin{array}{l}
{\left[\begin{array}{l}
\cos ^{2} \pi \frac{n a}{L} \\
+\sinh ^{2} \pi \frac{(H-b)}{L}
\end{array}\right] *\left[\begin{array}{l}
\cos ^{2} \pi \frac{n a}{L} \\
+\sinh ^{2} \pi \frac{(H+b+2 D)}{L}
\end{array}\right]} \\
+c 5
\end{array}\right\}
$$


Mohamed.M. Sobeih, Ibrahim M. Rashwan , Moustafa.A. El-Enany, Eman .M. Foda, "Improvement of ..."

The above equations may be rewritten as follows:

$K(d 1 / 2)=M^{\delta} 1+m(\delta 2+\delta 3)+C 5$

$K(b-d 2 / 2)=M \delta_{4+m}(\delta 5+\delta 6)+C 5$

$K(H)=M^{\delta 7}+m(\delta 8+\delta 9)+C 5$

Where:

$\delta 1=\frac{1}{2} \cdot \operatorname{In}\left[\begin{array}{l}\sinh ^{2} \frac{\pi d 1}{2 L} \\ * \sinh ^{2} \pi \frac{(d 1 / 2+2 D)}{L}\end{array}\right]$
$\delta 2=\frac{1}{2} \cdot \operatorname{In}\left[\begin{array}{l}\sinh ^{2} \pi \frac{(d 1 / 2-b)}{L} \\ * \sinh ^{2} \pi \frac{(d 1 / 2+b+2 D)}{L}\end{array}\right]$

$\delta 3=\sum_{1}^{n} \operatorname{In}\left\{\begin{array}{l}{\left[\begin{array}{l}\sin ^{2} \pi \frac{n a}{L} \\ +\sinh ^{2} \pi \frac{(d 1 / 2-b)}{L}\end{array}\right]} \\ *\left[\begin{array}{l}\sin ^{2} \pi \frac{n a}{L} \\ +\sinh ^{2} \pi \frac{(d 1 / 2+b+2 D)}{L}\end{array}\right]\end{array}\right\}$

$\delta 4=\frac{1}{2} \cdot \operatorname{In}\left[\begin{array}{l}\sinh ^{2} \frac{\pi(b-d 2 / 2)}{L} \\ * \sinh ^{2} \pi \frac{(b+2 D-d 2 / 2)}{L}\end{array}\right]$

$\delta 5=\frac{1}{2} \cdot \operatorname{In}\left[\begin{array}{l}\sinh ^{2} \pi \frac{(-d 2 / 2)}{L} \\ * \sinh ^{2} \pi \frac{(2 b+2 D-d 2 / 2)}{L}\end{array}\right]$

$\delta 6=\sum_{1}^{n} \operatorname{In}\left\{\begin{array}{l}{\left[\begin{array}{l}\sin ^{2} \pi \frac{n a}{L} \\ +\sinh ^{2} \pi \frac{(-d 2 / 2)}{L}\end{array}\right]} \\ *\left[\begin{array}{l}\sin ^{2} \pi \frac{n a}{L} \\ +\sinh ^{2} \pi \frac{(2 b+2 D-d 2 / 2)}{L}\end{array}\right]\end{array}\right\}$

$\delta 7=\frac{1}{2} \cdot \operatorname{In}\left[\begin{array}{l}\cosh ^{2} \frac{\pi H}{L} \\ * \cosh ^{2} \pi \frac{(H+2 D)}{L}\end{array}\right]$ $\delta 8=\frac{1}{2} \sum_{0}^{n} \operatorname{In}\left\{\begin{array}{l}{\left[\begin{array}{l}\cos ^{2} \pi \frac{n a}{L} \\ +\sinh ^{2} \pi \frac{(H-b)}{L}\end{array}\right]} \\ {\left[\begin{array}{l}\cos ^{2} \pi \frac{n a}{L} \\ +\sinh ^{2} \pi \frac{(H+b+2 D)}{L}\end{array}\right]}\end{array}\right\}$

$$
\delta 9=\frac{1}{2} \sum_{1}^{n} \operatorname{In}\left\{\begin{array}{l}
{\left[\begin{array}{l}
\cos ^{2} \pi \frac{n a}{L} \\
+\sinh ^{2} \pi \frac{(H-b)}{L}
\end{array}\right]} \\
{\left[\begin{array}{l}
\cos ^{2} \pi \frac{n a}{L} \\
+\sinh ^{2} \pi \frac{(H+b+2 D)}{L}
\end{array}\right]}
\end{array}\right\}
$$

From Eqs. (18) and (20) we get:

$$
\begin{aligned}
K(\mathrm{H}-\mathrm{d} 1 / 2) & =\mathrm{M}\left(\delta 7_{-} \delta 1_{1}\right) \\
& +\mathrm{m}\left(\delta_{8_{+}} \delta_{9-} \delta_{3-} \delta_{2}\right)
\end{aligned}
$$

Also, from Eqs. (19) and (20) we get

$$
\begin{aligned}
K(\mathrm{H}-\mathrm{b}+\mathrm{d} 2 / 2) & =\mathrm{M}\left(\delta_{7-} \delta_{4}\right) \\
& +\mathrm{m}\left(\delta_{8+} \delta_{9-} \delta_{5+} \delta_{6}\right)
\end{aligned}
$$

The above equations may be again rewritten as,

$\mathrm{Kx} 1=\mathrm{M} \quad \eta 1+\mathrm{m} \eta 2$

$\mathrm{K} \mathrm{x} 2=\mathrm{M} \quad \eta 3+\mathrm{m} \quad \eta 4$

Where:

$\mathrm{x} 1=(\mathrm{H}-\mathrm{d} 1 / 2)$

$\mathrm{x} 2=(\mathrm{H}-\mathrm{b}+\mathrm{d} 2 / 2)$

$\eta 1=\delta_{7-} \delta_{1}$

$\eta 2=\delta_{8+} \delta_{9-} \delta_{3-} \delta_{2}$

$\eta 3=\delta_{7-} \delta_{4}$

$\eta 4=\delta_{8+} \delta_{9-} \delta_{5-} \delta_{6}$

The strength $\mathrm{M}$ is given by:

$\mathrm{M}=\mathrm{K}^{\theta}$

Substituting from (25) into (23) and solving for $\mathrm{m}$ yields:

$\mathrm{m}=\mathrm{K}\left(\mathrm{x} 1-\eta 1^{\theta}\right) / \eta 2$

Substituting from (25) and (26) into (24) and solving for $\theta$ yields:

$\theta=(\mathrm{x} 1 \eta 4-\mathrm{x} 2 \eta 2) /(\eta 1 \eta 4-\eta 2 \eta 3)$ 
If the water table exists in the upper soil layer above the mole drains, the discharge reaching each unit length of mole drain is given by:

$\mathrm{Qm}=2 \pi \mathrm{k}(\mathrm{x} 1-\eta 1 \theta) / \eta 2$

Also, the discharge reaching each unit length of tile drain is given by:

$\mathrm{Qt}=2 \pi{ }_{\mathrm{k}} \theta$

\section{EFFECT OF THE VARIOUS PARAMETERS ON THE DRAIN DISCHARGE}

It was found from Eqs. (28) and (29) that the discharge per unit length of tile drain or mole drain is affected by certain parameters such as b, H, D,... .....ect.

In the following, we shall discuss the effect of the principal parameters on the discharge per unit length of tile drain and the discharge per unit length of mole drain.

\section{A. Effect of the soil thickness, D,}

Figure 3, illustrates the effect of the top clay cap thickness below tile drains on the discharge per unit length of both tile drains and mole drains. It is evident that the discharge per unit length of tile drains increases by $29 \%$ as the top clay cap thickness increases by $200 \%$ (from $6 \mathrm{~m}$ to $18 \mathrm{~m}$ ). Also, the discharge per unit length of mole drains decreases by $96 \%$ as the top clay cap thickness increases. From Fig. 3, it is evident that the discharge of the mole drains is affected more by increasing soil thickness than the discharge of tile drains.

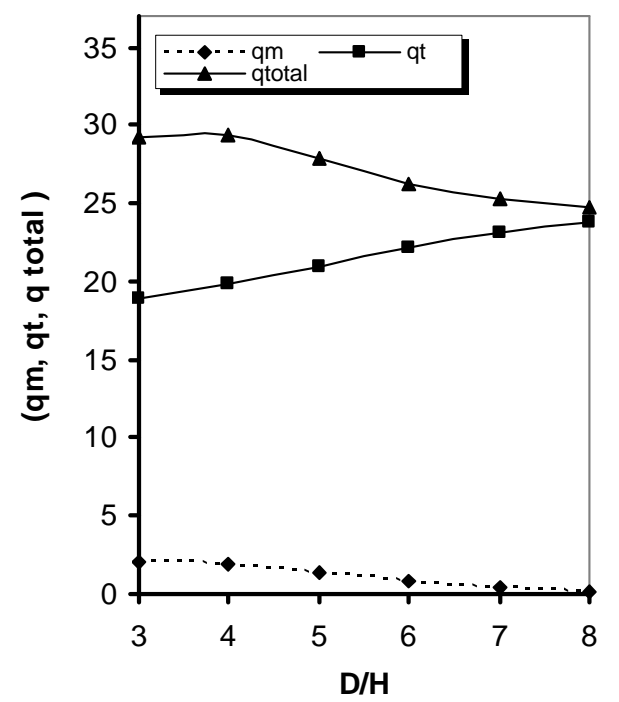

Fig. 3 Discharge ratio of tile drains and mole drains versus $\mathrm{D} / \mathrm{H}$ ratio $(\mathrm{a}=9 \mathrm{~m})$

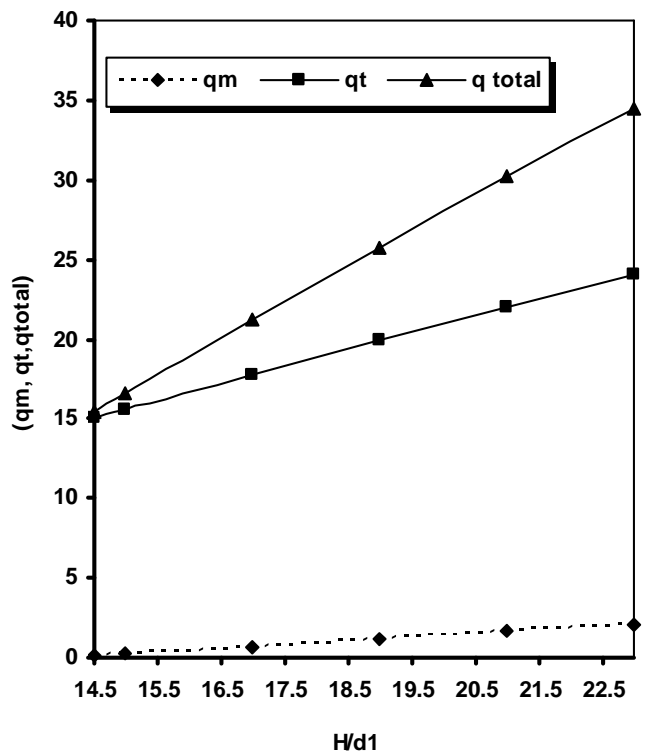

Fig. 4 Discharge ratio of tile drains and mole drains versus the effective head ratio,H/d1

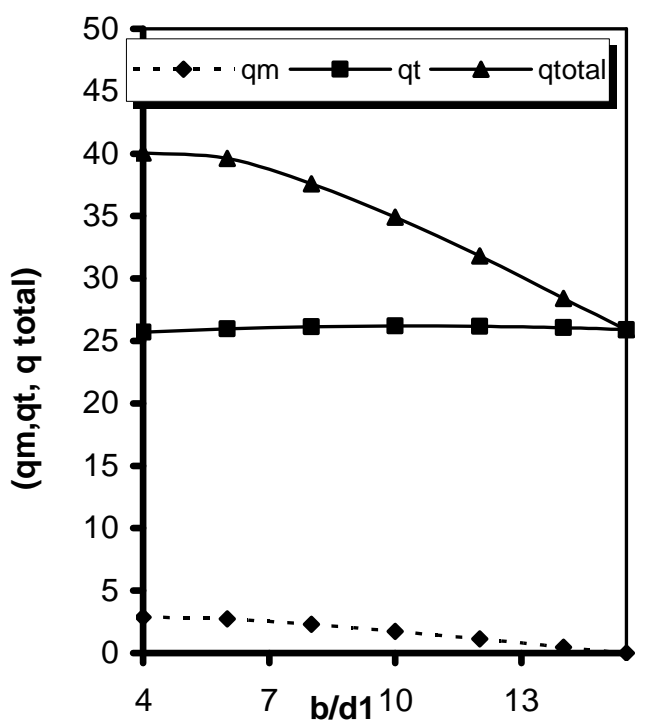

Fig. 5 Discharge ratio of tile drains and mole drains versus the vertical distance ratio, $b / d 1$

\section{B. EFFECT OF THE WATER HEAD, H,}

Figure 4 illustrates the relationship between the discharge the water table height. As the water head, $\mathrm{H}$, increases the discharge per unit length of both tile drains and mole drains increases, which should be expected since $\mathrm{H}$ represents the effective head causing flow towards tile drains and mole drains. 


\section{EFFECT OF THE VERTICAL DISTANCE, b,}

The effect of increasing the depth of tile drains below mole drains, b, on drains discharges is shown in Fig. 5. It is evident that as b increases, mole drains discharge per unit length significantly decreases because the effective head acting on mole drains, $\mathrm{H}$, decreases. on the other hand a slight increase in tile drains discharge per unit length occurs as $b$ increases.

\section{EFFECT OF THE MOLE DRAINS SPACING, a,}

The effect of mole drains spacing, a, is illustrated in Fig. 6. From Fig. 6, it is evident that when mole drains spacing decreases by $80 \%$ (from $15 \mathrm{~m}$ to $3 \mathrm{~m}$ ), the discharge per unit length of mole drains decreases by $73 \%$, but the discharge per unit length of tile drains increases by $6 \%$. Also, the total discharge for the system of mole drains and tile drains is increased by $13 \%$.

\section{E. EFFECT OF THE MOLE DRAINS DAIMETER, d2,}

Figure 7 represents the relationship between the discharge ratio of both tile drains and mole drains versus the mole drains diameter, d2. From Fig. 7, it is clear that the rate of change of the discharge of both mole drains and tile drains increase with increasing the mole drain diameter. When mole drains diameter increased from $0.02 \mathrm{~m}$ to $0.1 \mathrm{~m}$, the mole drain discharge per unit length is increased by $23 \%$, but the tile drain discharge per unit length is increased by $0.2 \%$ only and the total discharge for the system of mole drains and tile drains is increased by $5 \%$.

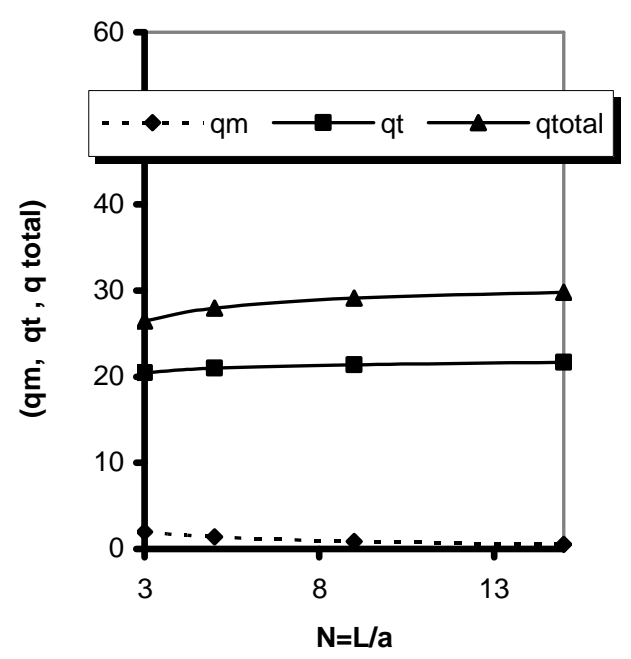

Fig. 6 Discharge ratio of tile drains and mole drains versus the number of mole drains, $\mathrm{N}$

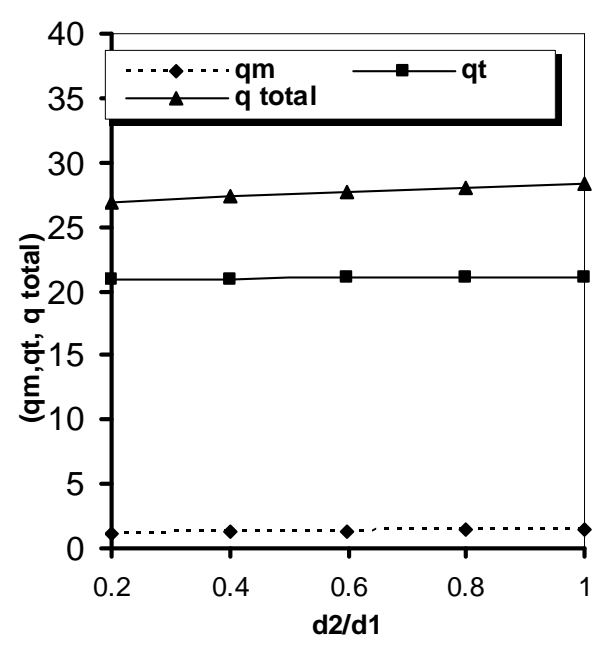

Fig. 7 Discharge ratio of tile drains and mole drains versus mole diameter ratio $\mathrm{d} 2 / \mathrm{d} 1$

\section{CONCLUSIONS}

Anew improvement for an existing tile drainage system using mole drains to protect an agricultural heavy clay layer of low hydraulic conductivity overlying an impermeable layer is established in this paper. The complex potential, the stream function, and the velocity potential are provided using the theory of complex functions and the theory of images. New discharge formulas for both tile and mole drains are established. Formulas by means of which velocity components at any point nay be calculated are provided. Effects of the different variables, the top clay cap thickness below drain center , D, mole drain diameter, $\mathrm{d} 2$, height of water above tile drain center midway between two successive tile drains, $\mathrm{H}$, vertical distance between mole drains and tile drains (b)and the spacing between mole drains (a) are studied. Graphs are provided to illustrate the relation between the discharge per unit length of drain and each of the involved parameters. From the above relations, it is clear that the best economical achievement occurs when the small vertical distance, $b$, is used.

\section{REFRENCES}

[1] Christen, E.W., and Ayars, J.E., (2001). "Subsurface drainage system design and management in irrigated agriculture :Best Management Practices for reducing drainage volume and salt load.," Technical Report 38/01,CSIRO Land and Water, Griffith, NSW, Australia .

[2] Hammad, H. Y., (1957) "Fluid Mechanics" Almaaref bst., Alex., 1957. 
[3] Hammad, H. Y., (1962) "Depth and Spacing of Tile Drain Systems.", Journal of Irrigation and Drainage Division Proceedings of the A.S.C.E .

[4] Hathoot, H. M.,and Sobeih, M., (1989). "Tile Drainage Assisted by Mole Drainage and Natural Drainage ," Alexandria Engrg. J.Alexandria, Egypt, 28(4), 57-82.

[5] Hathoot, H.M., (1978) . "Analysis of Double Mole Drain System .I " The First Conference on Fluid Mechanics, Faculty of Engineering, ElMansoura University.

[6] Hathoot, H.M., (1978) ." Analysis of Double Mole Drain Systems II The Bulletin of Faculty of Engineering, Alex. University,

[7] Hathoot, H.M., (1979). "Analysis of Double Mole Drain Systems III.", The Bulletin of Faculty of Engineering, Alex. University,

[8] Nijiland,H. J., Croon,F. W., and Ritzema,H. P., (2005). "Subsurface Drainage Practices : Guidelines for the implementation, operation and maintenance of subsurface pipe drainage systems. ,"Wageningen, alterra, ILRI Publication No.60, pp.608.

[9] Sobeih, M., (1988). "Improvement of Tile Drains by Using Double Mole Drains for Land Under Artesian Pressure." Mansoura Eng. Journal (MEJ) Vol. 13,No. 2

[10] Sobeih, M., (1988). "Improvement of Tile Drains by Using Mole Drains for Soil Subjected to Artesian Water Tabels." Mansoura Eng. Journal (MEJ) Vol. 13,No. 1

[11] Sobeih, M., (1989). "The Drains Assisted by Double Mole Drains." Mansoura Eng. Journal (MEJ) Vol. 14.

\section{APPENDIX NOTATION}

The following symbols have been adopted for use in the paper:

$\mathrm{a}=$ spacing between two successive mole drains,

$\mathrm{b}=$ vertical spacing between lines of tile drains and mole drains,

$\mathrm{Co}_{2}=$ carbon dioxide

$\mathrm{D}=$ depth of clay layer below the tile drain,

$\mathrm{d} 1=$ drain diameter for tile drains,

$\mathrm{d} 2=$ drain diameter for mole drains, $\mathrm{g}=$ acceleration due to gravity,

$\mathrm{H}=$ height of water table above tile drains at the mid point,

$i=\sqrt{-1}$,

$\mathrm{k}=$ hydraulic conductivity of soil,

$\mathrm{L}=$ spacing between two successive tile drains,

$\mathrm{M}=$ strength of a point sink representing a tile drain,

$\mathrm{m}=$ strength of a point sink representing a mole drain,

$\mathrm{n}=$ quantity $=[(\mathrm{L} / \mathrm{a})-1] / 2$,

$\mathrm{P}=$ pressure at any general point $(\mathrm{x}, \mathrm{y})$,

$\mathrm{Qm}=$ discharge reaching each unit length of mole drains,

$\mathrm{Qt}=$ discharge reaching each unit length of tile drains, $\mathrm{qm}=$ discharge ratio of mole drains $=\mathrm{Qm} /\left(k^{*} \mathrm{~d} 1\right)$, $\mathrm{qt}=$ Discharge ratio of tile drains $=\mathrm{Qt} /\left(k^{*} \mathrm{~d} 1\right)$, $\mathrm{q}$ total $=$ total discharge ratio of the system $=q t+(L / a) q m$,

$\mathrm{u}=$ velocity component in the $\mathrm{x}$ direction, $\mathrm{v}=$ velocity component in the $\mathrm{y}$ direction,

$\omega=$ complex potential $=\Phi+i \psi$,

$(\mathrm{x}, \mathrm{y})=$ coordinates of any point in the field of seepage,

$\mathrm{z}=$ complex number $=(\mathrm{x}+\mathrm{iy})$,

$\Phi=$ velocity potential,

$\Psi=$ stream function, and

$\rho=$ Water density 